\title{
La libre competencia económica en el régimen jurídico de los servicios públicos
}

Sebastián Barreto ${ }^{1}$

\section{RESUMEN}

Este artículo estudia el régimen jurídico de los servicios públicos para constatar la presencia de la libre competencia como concepto jurídico y técnicoeconómico. El artículo se concentra en los servicios públicos domiciliarios y de telecomunicaciones, los cuales fueron expresamente liberalizados por la ley, y da cuenta de algunas decisiones judiciales y administrativas que han fortalecido o atentado contra la libre competencia en esos sectores. Particularmente se observan el régimen jurídico de los contratos de las empresas de servicios públicos domiciliarios y las potestades de la autoridad de competencia en los mismos; para los servicios de telecomunicaciones se analizó la decisión del Consejo de Estado en el caso del tercer canal.

Palabras clave: Libre competencia, Servicios públicos, Igualdad de condiciones, Interpretación pro competencia, In dubio pro concurrentia.

1 Abogado de la Universidad Externado de Colombia, Bogotá, Colombia. Magíster en Derecho de la Universidad de Nottingham, Nottingham, Reino Unido. Candidato a doctor en Derecho de la Universidad de Nottingham, Nottingham, Reino Unido. Docente investigador del Departamento de Derecho Administrativo de la Universidad Externado de Colombia, Bogotá, Colombia. Correo-e: carlos.barreto@uexternado.edu.co Fecha de recepción: 22 de febrero de 2017. Fecha de modificación: 20 de marzo de 2017. Fecha de aceptación: 30 de mayo de 2017. Para citar el artículo: BARRETO, S., "La libre competencia económica en el régimen de los servicios públicos", Revista digital de Derecho Administrativo, n. ${ }^{\circ} 18$, segundo semestre, Universidad Externado de Colombia, 2017, pp. 225-252. DOI: https://doi.org/10.18601/21452946.n18.10 


\title{
Economic Competition in the Public Utilities Law Regime
}

\begin{abstract}
This paper analyses the role of competition as a legal and economic criterion in the legal regime of public utilities. It focuses in the public utilities and telecommunications services, because they were liberalised by the law in Colombia. The article also analyses some judicial and administrative decisions that have strengthened or weakened the role of competition in these economic activities. In particular, it examines the law of contracts of the enterprises in the public utilities sector; the powers of the competition authority in the public utilities sector; and the recent decision of the Council of State regarding a third TV channel for the telecommunications sector.
\end{abstract}

Keywords: Competition, Public Utilities, Level Playing Field, pro competition Interpretation of the Law, In dubio pro concurrentia.

\section{INTRODUCCIÓN}

La Constitución de 1991 supuso un paso fundamental hacia la liberalización de los servicios públicos, y como consecuencia de ello se creó un escenario de libre competencia en ese sector. Esto ha sido señalado por expertos en servicios públicos y derecho administrativo en diversas ocasiones ${ }^{2}$.

A pesar de lo anterior, cuando se hace un acercamiento un poco mayor a la doctrina sobre servicios públicos en Colombia, lo que se evidencia es que la existencia de la libre competencia, que es una realidad teórica jurídica, no ha sido analizada en el régimen jurídico que se ha impuesto al sector.

2 Alberto Montaña Plata, El concepto de servicio público en el derecho administrativo, Bogotá: Universidad Externado de Colombia, 2005, p. 100; Alberto Montaña Plata, "Alcances de la libertad económica privada en el régimen de servicios públicos introducido por la Constitución de 1991", Revista Derecho del Estado, Universidad Externado de Colombia, vol. 14, 2003, p. 197; Alberto Montaña Plata, "La desconfiguración del régimen jurídico de los servicios públicos domiciliarios a partir de la calificación de entidades públicas a las empresas de servicios públicos mixtas", Revista digital de Derecho Administrativo, Universidad Externado de Colombia, vol. 3, 2010, p. 165; Henry QuiJAnO, "Propuesta de reformas institucionales, legislativas y regulatorias a la política pública de servicios públicos domiciliarios de agua potable y saneamiento", Ópera, Bogotá: Universidad Externado de Colombia, n. ${ }^{\circ} 4$, 2004, Gulllermo Vargas Ayala, "El control judicial del contencioso administrativo en servicios públicos", Con-texto, Universidad Externado de Colombia, 2014, n. ${ }^{\circ} 42$, p. 15. 
En otras palabras, salvo comentarios en textos dedicados a otros temas ${ }^{3}$, no se conoce la existencia de un estudio jurídico sobre cómo la competencia como concepto jurídico y técnico-económico ha impactado el régimen jurídico de los servicios públicos, como sí existe para otros temas en otras latitudes ${ }^{4}$.

Este artículo se adentra en algunos temas concretos del régimen jurídico de los servicios públicos para observar en ellos la manifestación o la falta de manifestación de la libertad de competencia. Al respecto es importante anotar que este no es un estudio exhaustivo en el que se pretenda identificar todas las manifestaciones de la competencia en el régimen jurídico de los servicios públicos, sino un estudio que tiene por objeto analizar algunos casos puntuales que merecen especial atención debido a ciertas decisiones recientes que subrayan su importancia.

Debe aclararse que en este artículo no se hace mención a las ventajas o desventajas de la liberalización y la competencia en la prestación de los servicios públicos. El punto ha sido debatido extensamente en literatura ${ }^{5}$ y, sea cual sea nuestra posición al respecto, la realidad de nuestro régimen legal y constitucional es clara sobre la existencia de un modelo liberalizado en el cual existe libre competencia económica.

En suma, el análisis presentado se contrae a analizar algunas manifestaciones de la competencia en el régimen de los servicios públicos, independientemente del contenido ideológico que dicho concepto tiene como realidad extra jurídica ${ }^{6}$.

3 Alberto Montaña Plata, "La desconfiguración del régimen jurídico de los servicios públicos domiciliarios a partir de la calificación de entidades públicas a las empresas de servicios públicos mixtas", cit., p. 180.

4 Albert Sánchez Graells, Public Procurement and the EU Competition Rules, Oxford: Hart Publishing, 2015.

5 Giuseppe Bognetti y Gabriel Obermann, "Liberalization and privatization of public utilities: Origins of the debate, current issues and challenges for the future", Annals of Public and Cooperative Economics, vol. 79, n. ${ }^{\circ} 3-4,2008$, pp. 461-485; Jefrerey Delmon, "Approaches to private participation in water services: A toolkit", Washington, D.C.: World Bank, 2006, disponible en: http://ppp.worldbank.org/public-private-partnership/sites/ppp.worldbank. org/files/ppp_testdumb/documents/ApproachestoPrivateParticipationWaterServices.pdf [consultado el 5 de mayo de 2017]; Mary Shirley y Patrick Walsh, "Public versus private ownership: The current state of the debate", Working paper, World Bank, 2001; GaBRIEL Bitrán y Eduardo Valenzuela, "Water services in Chile: Comparing private and public performance", Washington, D.C.: The World Bank, 2003, disponible en: http://documents. worldbank.org/curated/en/455861468769468006/pdf/261260viewpoint.pdf [consultado el 5 de mayo de 2017].

6 Alison Jones y Brenda Sufrin, EU Competition Law: Text, Cases and Materials, Oxford: Oxford University Press, 5. ${ }^{\text {e }}$ ed., 2016, p. 21. 


\section{LA REALIDAD CONSTITUCIONAL Y LEGAL DE LOS SERVICIOS PÚBLICOS, EL ORIGEN DE LA COMPETENCIA EN EL SECTOR}

En los años 1990 en Colombia se presentó un fenómeno conocido como la "apertura económica"7. Entre las múltiples medidas, causa y consecuencia a la vez de esa apertura se encuentra la Constitución de 1991. Esta contiene diversas disposiciones que conforman la Constitución económica ${ }^{8}$, siendo importante traer a colación el artículo $365^{[9]}$.

Esta norma constitucional expresamente establece que los servicios públicos pueden ser prestados por particulares; es decir, los particulares tienen expresa habilitación constitucional para prestar servicios públicos, lo que, según ha expresado parte de la doctrina, puede revestir a la actividad de un contenido económico ${ }^{10}$. En contraposición, otro sector de la doctrina ha indicado que es posible que el régimen que fije la ley no reconozca la connotación económica del sector, a pesar de que se admita la prestación por parte de particulares, o incluso puede que no se reconozca la libre entrada de los particulares en absoluto ${ }^{11}$.

Bajo la premisa de que la Constitución lo admite, se abrió la puerta para que a los servicios públicos se apliquen las garantías que aquella otorga a las actividades económicas en general. La lógica es del siguiente tenor: la Constitución tiene ciertas garantías para las actividades económicas, y los servicios públicos según la propia Carta Política pueden tener connotación de actividad económica ${ }^{12}$; luego, las garantías constitucionales que se predican de las acti-

7 José GarCía, "Liberalización, cambio estructural y crecimiento económico en Colombia", Cuadernos de Economía, Bogotá: Universidad Nacional de Colombia, vol. 21, n. ${ }^{\circ} 36,2002$, p. 189.

8 Gaspar Ariño, Principios de derecho público económico, Bogotá: Universidad Externado de Colombia, 2003, p. 175.

9 "Los servicios públicos son inherentes a la finalidad social del Estado. Es deber del Estado asegurar su prestación eficiente a todos los habitantes del territorio nacional.

"Los servicios públicos estarán sometidos al régimen jurídico que fije la ley, podrán ser prestados por el Estado, directa o indirectamente, por comunidades organizadas, o por particulares. En todo caso, el Estado mantendrá la regulación, el control y la vigilancia de dichos servicios. Si por razones de soberanía o de interés social, el Estado, mediante ley aprobada por la mayoría de los miembros de una y otra cámara, por iniciativa del Gobierno decide reservarse determinadas actividades estratégicas o servicios públicos, deberá indemnizar previa y plenamente a las personas que en virtud de dicha ley, queden privadas del ejercicio de una actividad lícita".

10 Alberto Montaña Plata, El concepto de servicio público en el derecho administrativo, cit., p. 101.

11 JoRGE IVÁN RINCÓN CÓRDOBA, "La igualdad material como responsabilidad de la administración pública", en Alberto Montaña Plata y Andrés Fernando Ospina Garzón (eds. ), La constitucionalización del derecho administrativo, XV Jornadas Internacionales de Derecho Administrativo, Bogotá: Universidad Externado de Colombia, 2014, p. 430.

12 Es importante resaltar que esta no es la única connotación de los servicios públicos, pero es la que interesa para los propósitos de este escrito. 
vidades económicas en general, también se predican de los servicios públicos en tanto que actividades económicas.

Como lo han señalado la doctrina ${ }^{13}$ y la jurisprudencia nacionales ${ }^{14}$, la Constitución de 1991 no es neutra en relación con el modelo económico adoptado. Al punto que reconoce ciertos derechos y garantías.

Entre las múltiples garantías constitucionales que tienen las actividades económicas, en lo que interesa para los efectos de este artículo está la libertad de competencia. Así lo establece el artículo $333 \mathrm{CP}^{15}$. La Corte Constitucional ha concurrido en esta interpretación de la Constitución, y ha señalado que la libre competencia está constitucionalmente protegida en tanto expresión de la libre iniciativa privada ${ }^{16}$, y que esto se debe a que la Constitución optó por un modelo económico particular que privilegia la libre competencia en los mercados ${ }^{17}$.

En la doctrina también se puede encontrar referencia a la libre competencia como elemento fundante del sistema económico. Correa Henao ha dicho: "La libre competencia constituye el elemento sustancial del sistema económico establecido. Porque la economía de mercado para ser libre debe ser a la vez concurrente, ya que sólo con la competencia se asegura que el ejercicio de la iniciativa económica redundará en los resultados más eficientes y adecuados a los objetivos constitucionales"18.

A la luz de lo anterior se puede arribar a la conclusión de que la libre competencia económica es un derecho y una garantía expresamente establecida en la Constitución para las actividades económicas. En virtud de que el sector de los servicios públicos puede tener connotación de actividad económica, al menos a nivel constitucional, la libre competencia tendrá que existir como garantía para proteger la iniciativa privada en ese sector ${ }^{19}$.

13 Magdalena Correa Henao, Libertad de empresa en el Estado social de derecho, Bogotá: Universidad Externado de Colombia, 2008, p. 145; Rodrigo Uprimny y CésAR RodrígueZ, "Constitución y modelo económico en Colombia: hacia una discusión productiva entre economía y derecho", disponible en: http://www.dejusticia.org/files/r2_actividades_recursos/fi_name_recurso.775.pdf [consultado el 8 de mayo de 2017].

14 Entre otras, la sentencia de la Corte Constitucional C-535 de 1997.

15 "La actividad económica y la iniciativa privada son libres, dentro de los límites del bien común. Para su ejercicio, nadie podrá exigir permisos previos ni requisitos, sin autorización de la ley.

"La libre competencia económica es un derecho de todos que supone responsabilidades".

16 Sentencia de la Corte Constitucional C-815 de 2001, exp. D-3367.

17 Sentencia de la Corte Constitucional C-535 de 1997, exp. D-1598.

18 Magdalena Correa Henao, ob. cit., p. 157.

19 La Corte Constitucional ha señalado que en el caso de los servicios públicos que requieren para su prestación de un bien de uso público el Estado puede optar por la prestación directa, mixta o indirecta, y que, "[c]uando el Estado opta por la gestión de los bienes de uso público y de los servicios públicos a través del sistema de concesión, no nos encontramos, en el punto de partida, en el campo de la libertad económica, sino en el de 
Como se indicó en la introducción de este artículo, no se pretende hacer un análisis exhaustivo de todos los subsectores, ni de todos los casos en los cuales la competencia se manifiesta en el régimen de los servicios públicos. Por dicha razón solamente dos subsectores serán objeto de estudio.

Para el caso particular de los servicios públicos domiciliarios y los servicios de telecomunicaciones, dos especies del género servicios públicos, el legislador ha concretado la liberalización de los servicios públicos en el régimen legal. Es decir que entre las múltiples opciones disponibles, el legislador ha decidido aceptar en estos dos subsectores la libre entrada de los particulares, y les ha reconocido una connotación económica. Además, ha concretado en sus respectivos regímenes jurídicos el respeto por la libre competencia. Luego, la discusión en torno de la existencia de una connotación económica que se puede dar a nivel constitucional ${ }^{20}$ no existe para estos servicios en razón de que su particular régimen legal así lo establece.

\subsection{LA LIBERALIZACIÓN DE LOS SERVICIOS PÚBLICOS DOMICILIARIOS Y LA COMPETENCIA COMO PRINCIPIO LEGAL}

En el caso de los servicios públicos domiciliarios, la mencionada liberalización o habilitación general se encuentra en el artículo 10 de la Ley 142 de 1994. Dicho artículo señala que existe libertad de empresa en los servicios público domiciliarios ${ }^{21}$.

Como se indicó, la consecuencia de admitir la libre iniciativa privada en un sector es la necesidad de proteger dicha iniciativa por medio del reconocimiento de las garantías constitucionales, entre ellas la libre competencia. Así lo entendió también el legislador con la expedición de la Ley 142 de 1994, cuyo artículo 2 preceptúa que el Estado debe intervenir en estos servicios públicos con el fin de proteger la libre competencia y evitar el abuso de posición dominante ${ }^{22}$.

la función pública, no sólo porque la titularidad de la actividad es de naturaleza pública, sino también porque se trata de la satisfacción del interés público, para lo cual el legislador puede establecer las condiciones y limitaciones necesarias para el logro de sus fines competenciales": Corte Constitucional. Sentencia C-815 de 2001. En nuestra opinión, el hecho de que el punto de partida no sea la libertad económica sino la función pública no quiere decir que la connotación económica no exista. Por el contrario, lo que se está indicando es que existe la libertad económica, pero prima la función pública. Se considera innecesaria esta aclaración para llegar a la conclusión de que el legislador puede establecer limitaciones, puesto que en cualquier caso la libertad económica, se aclare o no que no es el punto de partida, está sometida a las limitaciones que el legislador decida imponerle.

20 Jorge IvÁn Rincón CóRdoba, ob. cit.

21 "Libertad de empresa. Es derecho de todas las personas organizar y operar empresas que tengan por objeto la prestación de los servicios públicos, dentro de los límites de la Constitución y la ley".

22 "Intervención del Estado en los servicios públicos. El Estado intervendrá en los servicios públicos, conforme a las reglas de competencia de que trata esta Ley, en el marco de 
El respeto por la libre competencia no se establece como un principio orientador del sector, sino como una de las finalidades que justifican la intervención del Estado en los servicios públicos domiciliarios. A pesar de la inexistencia de una norma que establezca que la competencia es una garantía, el hecho de que se requiera la intervención del Estado para protegerla, permite inferir que tiene esta naturaleza.

Se puede concluir entonces que el legislador desarrolló la Constitución de tal manera que tanto la libre iniciativa privada como la competencia tienen rango legal para los servicios públicos domiciliarios; consecuencialmente, estas garantías constitucionales aplican con todo su rigor en este sector. A la luz de lo anterior tiene sentido desde el punto de vista jurídico adentrarse en el régimen jurídico para observar las manifestaciones de la competencia. Labor esta última que no cabría de haberse establecido un régimen legal sin connotación económica como lo admitiría una lectura del artículo 365 como la presentada por Rincón Córdoba ${ }^{23}$.

\subsection{LA LibERALIZACIÓN DE LOS SERVICIOS DE TELECOMUNICACIONES Y LA COMPETENCIA COMO PRINCIPIO LEGAL}

De manera similar, para el caso de los servicios de telecomunicaciones existe habilitación general y el reconocimiento de la competencia como garantía para proteger la iniciativa privada. En efecto, la Ley 1341 de 2009 en el artículo $10^{[24]}$ reconoce de manera expresa una "habilitación general" ${ }^{2}$ esto es, la libertad de los particulares de prestar los servicios públicos de telecomunicaciones sin necesidad de ninguna habilitación adicional diferente de la ley ${ }^{25}$.

A pesar de lo anterior, existe una circunstancia que es importante resaltar, a saber, el hecho de que estos servicios son declarados "bajo la titularidad del Estado". Lo anterior implica que los particulares pueden concurrir a su prestación solamente bajo la existencia de un título habilitante: un contrato

lo dispuesto en los artículos 334, 336, y 365 a 370 de la Constitución Política, para los siguientes fines:

"[...]

"2.6. Libertad de competencia y no utilización abusiva de la posición dominante".

24 "A partir de la vigencia de la presente ley, la provisión de redes y servicios de telecomunicaciones, que es un servicio público bajo la titularidad del Estado, se habilita de manera general, y causará una contraprestación periódica a favor del Fondo de las Tecnologías de la Información y las Comunicaciones. Esta habilitación comprende, a su vez, la autorización para la instalación, ampliación, modificación, operación y explotación de redes de telecomunicaciones, se suministren o no al público. La habilitación a que hace referencia el presente artículo no incluye el derecho al uso del espectro radioeléctrico".

25 Alberto Montaña Plata, El concepto de servicio público en el derecho administrativo, cit., p. 100. 
de concesión o un acto administrativo de licencia ${ }^{26}$. Se puede decir que la norma es contradictoria pues al tiempo que otorga una habilitación general, establece que solamente puede ser prestado por los particulares cuando exista un título habilitante.

Esta contradicción pudo haber sido causada por una confusión entre la habilitación para prestar el servicio y el acceso al espectro radioeléctrico. Para entender la diferencia entre habilitación para prestar el servicio y acceso al espectro se considera necesario entender un poco la historia y estructura del sector.

Antes de la expedición de la Ley 1341 de 2009 el modelo predominante en los servicios de telecomunicaciones era un modelo de titularidad pública en el que los prestadores adquirían esta calidad solamente bajo la existencia de un título que los habilitara para ello: una licencia o una concesión ${ }^{27}$. Este título que los habilitaba para prestar el servicio no era suficiente para proceder a la prestación del mismo, pues era necesario además tener acceso al espectro radioeléctrico ${ }^{28}$. Esto, a pesar de que en ocasiones se otorgase el acceso al espectro en el mismo título que habilitaba para la prestación del servicio; ello era así como consecuencia de que el Estado era el titular tanto del servicio como del espectro necesario para la prestación del mismo; sin embargo, los dos conceptos son diferentes.

En términos generales, puede decirse que el acceso al espectro es un presupuesto material necesario para la prestación del servicio de telecomunicaciones, mientras que el título habilitante es un presupuesto jurídico. Si un prestador no tiene acceso al espectro radioeléctrico no puede prestar el servicio de telecomunicaciones porque no tiene los medios materiales para hacerlo. De otra parte, si un prestador no está habilitado para prestar el servicio no tiene la posibilidad jurídica de hacerlo, aun en caso de tener acceso al espectro.

La contradicción que se presenta en el artículo 10 parece provenir de la confusión del legislador entre la titularidad del servicio y el acceso al espectro. La idea de que este es el origen de la confusión y de que la Ley 1341 de 2009 en efecto estableció una habilitación general se puede derivar tanto del mismo artículo 10 como de la exposición de motivos del proyecto que se convertiría en esa ley.

El artículo 10 establece al final: "La habilitación a que hace referencia el presente artículo no incluye el derecho al uso del espectro radioeléctrico". Esta aclaración no es necesaria si se tiene en consideración que la habilitación para prestar el servicio no es sinónimo, ni lo ha sido nunca, de acceso al espectro. Pero el hecho de que el legislador la haya incluido refuerza la idea

Ibíd.

27 Así los artículos 2 y 4 del Decreto 1900 de 1990 y 4 y 5 de la Ley 555 de 2000.

28 Ver, entre otros, artículo 20 del Decreto Ley 1900 de 1990. 
de que cuando declaró que el servicio de telecomunicaciones estaba "bajo la titularidad del Estado", en realidad se hacía referencia a la titularidad sobre el bien de uso público, el espectro radioeléctrico ${ }^{29}$.

Adicionalmente, la primera vez en el proceso legislativo que se encuentra referencia a la "titularidad pública" al lado de la "habilitación general" es en el segundo debate que se dio en el Senado de la República ${ }^{30}$. Es decir que durante todo el proceso surtido en la Cámara de Representantes no existió referencia a la "titularidad del Estado", sino simplemente a la habilitación general y las normas relativas al acceso al espectro. Luego, el verdadero objeto del proyecto fue la habilitación general.

Para desentrañar el alcance de esta habilitación general, y de la contradictoria titularidad pública, se puede observar la exposición de motivos del proyecto de ley. En el mencionado proyecto se señaló: "Adicionalmente, en la medida que el sector migra hacia un modelo de competencia mayorista de infraestructura que sirve de soporte a una amplia gama de proveedores minoristas de servicios y aplicaciones, la migración hacia procesos de habilitación general y con neutralidad tecnológica resulta fundamental para la eliminación de barreras de entrada administrativas" ${ }^{\prime 31}$.

Lo anterior quiere decir que la realidad del mundo de las TIC se estaba modificando de tal manera que quienes tenían acceso directo al espectro no eran necesariamente los únicos prestadores del servicio. Como lo indica el párrafo transcrito, un grupo de mayoristas con acceso al espectro y dueños de la infraestructura física podían servir de soporte a un grupo de minoristas que prestaban los servicios al público.

En ese orden de ideas, un esquema en donde solo podían prestar el servicio quienes tuvieran un título habilitante resultaba vetusto, pues el Estado debía celebrar un contrato o expedir una licencia por cada potencial prestador. $\mathrm{Pa}$ ra evitar esto, el proyecto pretendía establecer una habilitación general con el objetivo de que los prestadores minoristas pudieran entrar directamente al mercado. Estos prestadores minoristas, a su vez, tendrían que negociar el acceso al espectro con los mayoristas, quienes tendrían el acceso directo al espectro en razón de un título expedido por el Estado.

29 Es importante mencionar que el espectro es un bien de uso público por expreso mandato constitucional. El artículo 75 superior establece: "Artículo 75. El espectro electromagnético es un bien público inenajenable e imprescriptible sujeto a la gestión y control del Estado. Se garantiza la igualdad de oportunidades en el acceso a su uso en los términos que fije la ley. "Para garantizar el pluralismo informativo y la competencia, el Estado intervendrá por mandato de la ley para evitar las prácticas monopolísticas en el uso del espectro electromagnético".

30 Ponencia para Segundo Debate al Proyecto de Ley 340 de 2008 Senado, 112 de 2007 Cámara, Gaceta del Congreso n. ${ }^{\circ} 487$ de 2009.

31 Ponencia para Primer Debate al Proyecto de Ley 112 de 2007 Cámara, Gaceta del Congreso n. ${ }^{\circ} 233$ de 2008 . 
De tal manera, el régimen legal separó por completo la habilitación para la prestación del servicio del acceso al espectro. Por lo tanto, la supuesta "titularidad" pública debe entenderse en el restringido ámbito del espectro, y no como una consideración general para la prestación del servicio. De lo contrario, se contradiría el espíritu de la ley y el objetivo del legislador.

Por otra parte, la misma Ley 1341 de 2009 estableció la libre competencia como un principio orientador en el artículo $2^{[32]}$.

De manera similar a lo concluido para los servicios públicos domiciliarios, para los servicios de telecomunicaciones se puede concluir que el régimen legal establece una habilitación general, lo cual se acompañó con la garantía de la libre competencia como principio orientador del régimen jurídico. Esto fortalece la idea de que no puede existir un sector en el cual se reconozca la libre iniciativa privada sin que se le acompañe de la libre competencia como garantía para lograr la materialización de los fines de la iniciativa privada. Finalmente, con la conclusión de que existe en los servicios públicos de telecomunicaciones la libre competencia como principio tiene lógica estudiar las manifestaciones de esta última en el régimen jurídico de los mismos.

\section{EL ANÁLISIS DE ALGUNAS MANIFESTACIONES PARTICULARES DE LA LIBRE COMPETENCIA EN EL RÉGIMEN DE LOS SERVICIOS PÚBLICOS}

El análisis que se ha hecho hasta este punto es simplemente un estudio de las realidades legales y constitucionales de dos especies distintas de servicios públicos: los de telecomunicaciones y los domiciliarios. Sin embargo, poco se aportaría a la doctrina si simplemente se subraya la existencia de normas que preceptúan la liberalización de esos servicios y la garantía de libre competencia en los mismos.

Este artículo pretende ir más allá, al analizar en casos concretos cómo se materializa ese principio denominado de libre competencia. El análisis de esos casos concretos, aunque con las normas legales y constitucionales como referente, se concentra en decisiones judiciales y administrativas. Lo anterior, bajo la premisa de que las formas de producción del derecho administrativo,

"Son principios orientadores de la presente ley:

"[...]

"2. Libre competencia. El Estado propiciará escenarios de libre y leal competencia que incentiven la inversión actual y futura en el sector de las TIC y que permitan la concurrencia al mercado, con observancia del régimen de competencia, bajo precios de mercado y en condiciones de igualdad. Sin perjuicio de lo anterior, el Estado no podrá fijar condiciones distintas ni privilegios a favor de unos competidores en situaciones similares a las de otros y propiciará la sana competencia". 
incluido el derecho de los servicios públicos, tienen un importante referente en la jurisprudencia y las decisiones de la Administración ${ }^{33}$.

Al igual que lo sucedido con el aparte primero, este dividirá el análisis en dos, con un acápite para cada especie de servicio público.

\subsection{Manifestaciones Particulares de la libre COMPETENCIA EN LOS SERVICIOS PÚBLICOS DOMICILIARIOS}

En el caso de los servicios públicos domiciliarios, la atención se concentrará en dos situaciones diferentes: la primera será el régimen jurídico de los actos y contratos de las empresas de servicios públicos domiciliarios; la segunda, la prohibición de ejecutar conductas contrarias a la libre competencia en el sector. En el primer caso la fuente principal de análisis serán las decisiones del Consejo de Estado sobre la materia, y en el segundo lo serán las decisiones de la Superintendencia de Industria y Comercio (SIC) en su calidad de autoridad nacional de competencia, es decir, actos administrativos. Se pretende que con el análisis de un grupo de decisiones judiciales y otro de decisiones administrativas se ilustre con suficiencia la realidad del régimen jurídico del sector, así como la aproximación que cada rama del poder público tiene a la competencia en el sector.

\subsubsection{El régimen jurídico de los actos y contratos de las empresas de servicios públicos y la libre competencia}

En primer lugar, debe señalarse que existen estudios sobre el régimen jurídico de los actos y contratos de las empresas de servicios públicos (ESP) que tocan el punto con mayor precisión y profundidad ${ }^{34}$. Es decir que en este escrito no se abordan todas las decisiones en las cuales se ha tratado el régimen de los actos y contratos de las empresas de servicios públicos. Sin embargo, correponde decir que los estudios existentes no han centrado su análisis en la libre competencia como criterio jurídico o técnico-económico, lo que confiere algo de novedad a la perspectiva que se acá se ofrece.

Un artículo de la Ley 142 de 1994 que normalmente pasa desapercibido en los estudios que se hacen sobre el régimen jurídico de las ESP es el artículo 30 , artículo que prescribe que las normas de esa ley que tratan sobre contratos

33 Juan Carlos Henao, "Estado social y derecho administrativo", en Alberto Montaña Plata y ANDRÉS FERNANDO OSPINA GARZÓn (eds.), La constitucionalización del derecho administrativo, XV Jornadas Internacionales de Derecho Administrativo, Bogotá: Universidad Externado de Colombia, 2014.

34 Alberto Montaña Plata, "La desconfiguración del régimen jurídico de los servicios públicos domiciliarios a partir de la calificación de entidades públicas a las empresas de servicios", cit.; Gulletermo Vargas Ayala, ob. cit. 
se deben interpretar con base en los principios previstos por dicha ley, y en la manera en que mejor se garantice la libre competencia y mejor se impidan los abusos de posición dominante ${ }^{35}$.

El legislador en este artículo impartió una orden expresa en el sentido de que la libre competencia es un principio de interpretación sobre el régimen legal de los contratos de las ESP. En otras palabras, los operadores jurídicos en la interpretación del régimen contractual establecido por la Ley 142 de 1994 deben consultar la libre competencia como criterio interpretativo; podría decirse que la norma legal establece una interpretación pro competencia o in dubio pro concurrentia de las normas referidas.

La lógica presentada a lo largo de la primera parte de este escrito se fortalece con la norma recién transcrita. La libre competencia no es solo una de las razones que justifican la intervención del Estado, sino que además debe ser un criterio de interpretación de la ley para los operadores jurídicos. La pregunta subsiguiente es si los operadores jurídicos en Colombia han respetado este principio legal al momento de interpretar el régimen de de las ESP. Para poder dar respuesta a esta pregunta es necesario consultar el contenido y espíritu de la Ley 142 de 1994 y analizar algunas decisiones jurisprudenciales sobre la materia.

Si se tratara de reducir a su esencia el propósito de la Ley 142 de 1994 se podría decir que intentó "atribuir una calificación orgánica única a los prestadores de los servicios públicos domiciliarios, capaz de soportar un régimen jurídico, también único" ${ }^{136}$.

De tal manera, esa norma legal pretendió establecer un prestador único, las ESP, y un régimen jurídico único. A pesar de la existencia en la mencionada ley de tres tipos de ESP, oficiales, mixtas y privadas, Montaña ha señalado que las diferencias entre los diversos tipos de ESP son muy pocas, y que tal proporción se justifica porque ante ciertas circunstancias no es posible tratar a sujetos públicos y privados de la misma manera ${ }^{37}$.

El régimen común de los prestadores se estableció en el artículo 32 de la Ley 142 de 1994, disposición que establece que salvo que la Constitución o la ley dispongan expresamente lo contrario, todos los actos de las ESP, así como

35 "Las normas que esta ley contiene sobre contratos se interpretarán de acuerdo con los principios que contiene el título preliminar; en la forma que mejor garantice la libre competencia y que mejor impida los abusos de la posición dominante, tal como ordena el artículo 333 de la Constitución Política, y que más favorezca la continuidad y calidad en la prestación de los servicios".

36 Alberto Montaña Plata, "La desconfiguración del régimen jurídico de los servicios públicos domiciliarios a partir de la calificación de entidades públicas a las empresas de servicios", cit., p. 164.

37 Alberto Montaña Plata, "La desconfiguración del régimen jurídico de los servicios públicos domiciliarios a partir de la calificación de entidades públicas a las empresas de servicios", cit., p. 164. 
los requeridos para su administración y el ejercicio de sus derechos, se regirán por el derecho privado ${ }^{38}$.

A la luz de lo anterior se puede concluir que la Ley 142 de 1994 pretendía establecer un régimen jurídico único para todos los prestadores sin importar la conformación de su capital. Ello era así como consecuencia de la necesidad de establecer condiciones similares entre los prestadores del servicio para que existiera una competencia justa en el mercado ${ }^{39}$; se trata de la necesidad de establecer un level playing field ${ }^{40}$. Ese régimen jurídico similar fue el derecho privado, salvo que la Constitución o la ley expresamente dispusieran lo contrario.

Con base en lo anterior se puede entrar a observar cuál ha sido la interpretación jurisprudencial de este régimen jurídico relativamente claro y de sus objetivos.

Una de las decisiones trascendentales sobre esta materia es la sentencia de la Corte Constitucional C-736 de 2007. En esa decisión la Corte se pronunció sobre la no inclusión de las empresas de servicios públicos mixtas en el sector descentralizado tal y como este fue definido por la Ley 489 de 1998. Lo anterior, pues solamente las ESP oficiales fueron incluidos en los artículos de la Ley 489 de 1998 referidos al sector descentralizado por servicios.

En esa decisión, la Corte decidió que las ESP mixtas y las privadas con capital público ${ }^{41}$ hacen parte de la rama ejecutiva del poder público. Adicionalmente, a esa infortunada lectura de la Ley 489 de 1998 la Corte le asignó algunas consecuencias, esto es, que esas empresas: estarían sometidas a control fiscali a control político; debían ser de creación legal, por medio de ordenanza o acuerdo según el nivel territorial; a ellas aplicaba el régimen de inhabilidades e incompatibilidades previsto en la Constitución; estaban sometidas a las reglas

"Salvo en cuanto la Constitución Política o esta Ley dispongan expresamente lo contrario, la constitución, y los actos de todas las empresas de servicios públicos, así como los requeridos para la administración y el ejercicio de los derechos de todas las personas que sean socias de ellas, en lo no dispuesto en esta Ley, se regirán exclusivamente por las reglas del derecho privado".

39 "Para ser consecuentes con el panorama constitucional de la liberalización de los servicios públicos y la consiguiente libre competencia entre los prestadores, se podría colegir que, en términos de técnica legislativa, la distinción de empresas (oficiales, mixtas y privadas) podía obviarse, para resultar coherente con aquél, eso sí, siempre con la atención del caso a la protección del capital público que pueda estar presente en algunas de ellas": Alberto Montana Plata, "La desconfiguración del régimen jurídico de los servicios públicos domiciliarios a partir de la calificación de entidades públicas a las empresas de servicios", cit., p. 164.

40 Richard Arneson, "Equality of opportunity", The Stanford Encyclopedia of Pbilosopby, Stanford: Stanford University, 2015, disponible en: https://plato.stanford.edu/cgi-bin/encyclopedia/ archinfo.cgi?entry=equal-opportunity

41 Así lo comparte también Montaña en la lectura que hace de esa decisión. AlberTo MonTaña Plata, "La desconfiguración del régimen jurídico de los servicios públicos domiciliarios a partir de la calificación de entidades públicas a las empresas de servicios", cit. 
orgánicas de presupuesto; ${ }_{i}$ en materia contable quedaban sujetas a la contabilidad oficial ${ }_{i}$ y además, estaban sujetas a control de tutela.

A la luz de lo anterior se puede afirmar que si las empresas mixtas tienen un régimen que incluye esas consecuencias en razón de que pertenecen a la rama ejecutiva, las empresas oficiales que por expresa determinación legal tienen el carácter de entidades descentralizadas ${ }^{42}$ también deben atenerse a esas reglas.

Analizar el impacto real que tiene imponer a determinadas empresas (aquellas con capital público) una carga adicional (las reglas recién mencionadas) requiere de un estudio empírico en el que se demuestren la ineficiencias que crean estas normas de derecho público. Sin embargo, desde el punto de vista jurídico resulta ineludible subrayar que esta lectura de la Corte Constitucional violenta la igualdad de condiciones de los agentes económicos en el mercado. En nuestra opinión, con esta lectura se soslayó por completo el principio de interpretación pro competencia establecido en la propia Ley 142 de 1994.

Algunos ejemplos generales de este quebrantamiento de la igualdad de condiciones de los actores en el mercado se darán para ilustrar el punto, con la advertencia de que el impacto real requiere un estudio ulterior, empírico, o cuando menos un análisis económico de las normas.

Resulta complejo conciliar la lógica de mercado que deben tener estas empresas con la posibilidad de que órganos de naturaleza política cuestionen sus decisiones empresariales. Esto es justamente lo que implica la posibilidad de controlar políticamente a estas empresas.

Otra situación que resulta compleja de cara al régimen privado es la necesidad de cumplir con las normas públicas presupuestarias. No existía disposición que indicase que dichas reglas debían ser cumplidas por las ESP; sin embargo, así lo dictaminó la Corte Constitucional. Esta realidad impone a las empresas con capital público cumplir con unas estrictas y rígidas normas de derecho público que están planteadas para el sector público, pero no para un sector que debe competir en igualdad de condiciones con particulares que no tienen reglas presupuestarias con similar rigidez.

Podemos concluir sobre esa decisión, con Montaña, que "[e]n la práctica, la atención de esta modificación significa, entonces, una flagrante discriminación entre agentes públicos y agentes privados, que en nuestra opinión atenta contra el derecho a la libre competencia del que son titulares los prestadores de servicios públicos de conformidad con lo establecido en el artículo 365 constitucional, en concordancia con el $333^{\prime \prime 4}$.

Esto atenta de manera frontal contra el principio de libertad de competencia en su manifestación de igualdad de condiciones de los actores en el mercado. Es domiciliarios a partir de la calificación de entidades públicas a las empresas de servicios", cit., p. 180. 
decir que con la decisión de la Corte sobre las empresas de servicios públicos se está atacando la propia lectura de la Corte sobre la libertad de competencia en otros sectores económicos, y en otras decisiones sobre servicios públicos.

En relación con el anterior punto, el Consejo de Estado ha considerado que lo señalado constituye obiter dicta de la decisión de la Corte Constitucional ${ }^{44}$. Por lo tanto, la mencionada carga normativa que desequilibra a los operadores públicos respecto de los privados no sería vinculante. Sin embargo, las dos interpretaciones permanecen en el ordenamiento hasta que no exista claridad en relación con el verdadero alcance de la decisión de la Corte.

Otra decisión del Consejo de Estado ${ }^{45}$ parece alinearse con la de la Corte Constitucional, en el sentido de diferenciar aún más los regímenes de las entidades que pueden ser consideradas entidades públicas de aquellas que pueden ser consideradas empresas privadas.

En esta ocasión las normas demandas eran unos actos, denominados "reglamento de contratación" y "condiciones generales para la contratación". En esta ocasión el Consejo de Estado dejó claro que su decisión se refería a un momento en el tiempo en el cual la empresa que había expedido estos actos era una empresa de servicios públicos oficiales, pues su capital era $100 \%$ público.

Lo que no resulta igual de claro es si las conclusiones que alcanza en relación con la naturaleza de los actos se contrae solo a este tipo de empresas, o si también podría predicarse de los tipos "públicos" bajo la comprensión de la sentencia C-736 de 2007, es decir, empresas mixtas y privadas con capital público.

A decir verdad, la argumentación del Consejo de Estado es escasa ${ }^{46}$. En esa ocasión el Consejo de Estado señaló que para que una manifestación de la voluntad sea controlable por parte de la jurisdicción han de concurrir dos requisitos: 1 . que provenga de autoridad o particular que cumpla funciones administrativas, y 2. que se observe un contenido decisorio, o lo que es igual, que produzca efectos. Seguidamente la sala concluye, sin referencia concreta al contenido de los actos, que los actos demandados son manifestaciones de voluntad de la Administración y que dichos actos se producen sin anuencia de los destinatarios, por lo que trazan reglas de conducta. Por lo tanto, concluye el Consejo de Estado que se trata de actos administrativos porque establecen reglas contractuales que se trazan para lograr la mejor prestación de los servicios públicos y de los fines del Estado.

44 Consejo de Estado, Sala de lo Contencioso Administrativo, Sección Tercera. Sentencia de 3 de diciembre de 2008, exp. 34745.

45 Consejo de Estado, Sala de lo Contencioso Administrativo, Sección Tercera. Subsección "C". Sentencia de 13 de abril de 2011, exp. 37423.

46 Consejo de Estado, Sala de lo Contencioso Administrativo, Sección Tercera, Subsección "C". Sentencia de 13 de abril de 2011, exp. 37423. 
En el numeral anterior el Consejo de Estado había llegado a la conclusión de que la ETB al momento de expedir estos actos era una empresa oficial. Sin embargo, cuando analiza la naturaleza de los actos parece que la naturaleza de la entidad es poco relevante y se centra en el hecho de que se trata de una expresión unilateral de voluntad de la Administración que produce efectos jurídicos, ligándolo a la prestación de servicios públicos y de cumplimiento de las finalidades del Estado. Por ello, no resulta claro si la decisión refiere a la ETB como administración en tanto empresa oficial, 100\% pública, o lo hace en tanto que prestadora de servicios públicos domiciliarios.

El punto trascendental es desentrañar si las empresas de servicios públicos en general son administración en tanto prestadoras de servicios públicos, o si las empresas de servicios públicos oficiales son administración en tanto pertenecen a la rama ejecutiva del poder público.

El alcance de esa decisión debería limitarse a las empresas de servicios públicos oficiales. En ese sentido parece estar la aclaración previa hecha dentro de la decisión en relación con la naturaleza oficial de la empresa.

Adicionalmente, esa decisión establece más diferencias entre los regímenes jurídicos de las ESP, y se considera más respetuoso de la libre competencia que sea diferenciación se dé solamente respecto del menor número de operadores posible, solamente aquellos oficiales.

Sea que se refiera solamente a las empresas oficiales o a todas las empresas con capital público, lo cierto es que el Consejo de Estado impuso un régimen de derecho público a ciertas empresas en la expedición de actos empresariales unilaterales. Todos los actos de carácter unilateral, como los demandados en la sentencia aludida, en los cuales se "observe un contenido decisorio, o lo que es igual, que produzca efectos", serán considerados actos administrativos. En nuestro sentir, si un reglamento interno de contratación y las "condiciones generales para la contratación" tienen para el Consejo de Estado un contenido decisorio, lo difícil será pensar en actos empresariales que no lo tengan.

A la luz de lo anterior, existe una discriminación entre operadores en relación con el régimen de sus actos empresariales. Esta discriminación tendrá como consecuencia una carga más pesada en el régimen jurídico para las empresas oficiales. Aun cuando se requiere un estudio empírico para medir las consecuencias reales de esta decisión, el simple hecho de que sus actos sean demandables por cualquier destinatario, por ejemplo un potencial contratista, crea costos adicionales, como el de defenderse de ello ante la jurisdicción de lo contencioso. Lo anterior se considera prueba suficiente de una desigualdad de condiciones en el mercado que violenta la competencia como principio y da cuenta del abandono del Consejo de Estado de la libre competencia como criterio interpretativo de las normas relativas a los contratos contenidas en la Ley 142 de 1994.

El Consejo de Estado pudo haber entendido el asunto de manera diferente. Por ejemplo, en una lectura de la orden del artículo 30 de la Ley 142 de 
1994, pudo haber decidido que la competencia como criterio interpretativo imponía que esos actos no podían ser considerados administrativos, puesto que de serlo se estaría estableciendo un régimen jurídico diferenciado entre empresas competidoras.

Adicionalmente, desde una perspectiva iusadministrativista más tradicional, es posible distinguir cuándo las administraciones actúan como administración y cuándo no. Luego, en el caso de empresas con capital público, incluso las oficiales, sería posible distinguir cuándo hacen uso de su calidad de entidades públicas y cuándo actúan como cualquier otra empresa en el mercado podría actuar. Es posible argumentar que los actos demandados en la sentencia que se critica son actos que cualquier empresa podría expedir para su uso interno, sin que sus potenciales contratistas pudiesen demandarlos ante la jurisdicción ordinaria. Luego, no se justifica que materialmente estos actos se categoricen como administrativos.

Así, podría recurrirse a la idea de que esos actos son expedidos por una administración, pero no en ejercicio de funciones administrativas, sino empresariales, subrayando el contenido económico de los servicios públicos. En efecto, cuando Santofimio ${ }^{47}$ define el acto administrativo señala que un elemento fundamental es el ejercicio de función administrativa. Función administrativa que no está presente en el caso de decisiones que cualquier empresa podría tomar, menos cuando el legislador claramente estableció un régimen de derecho privado por regla general.

A la luz de todo lo anterior es posible concluir que, a pesar de la lógica de la Ley 142 de 1994, y de la expresa orden de interpretar sus normas con la libre competencia como criterio, lo que se puede observar en la jurisprudencia es justamente el progresivo deterioro de ese régimen jurídico único, y con ello el progresivo menoscabo de los propósitos de la ley y de la competencia como criterio interpretativo.

\subsubsection{Conductas prohibidas por el régimen de competencia en los servicios públicos domiciliarios}

Otro aspecto relevante para el caso de los servicios públicos domiciliarios, y que es consecuencia directa de la existencia de libre competencia en este sector, es la aplicación de las normas del derecho de la competencia, una consecuencia quizás obvia pero por largo tiempo inadvertida.

La propia Ley 142 de 1994 en su artículo 34 establece unas normas especiales que constituyen los típicos ejemplos de prácticas restrictivas de la com-

47 Jaime Orlando Santofimio Gamboa, Tratado de derecho administrativo, Bogotá: Universidad Externado de Colombia, 2004. 
petencia ${ }^{48}$, y además abre la puerta para que también se apliquen las normas sobre competencia desleal.

La regla general de la Ley 142 es un régimen de libre entrada y de competencia en el mercado. Es decir, los prestadores no requieren de un permiso para convertirse en tales y pueden empezar a desarrollar su actividad económica siempre y cuando se constituyan como ESP y cumplan con los requisitos legales.

Sin embargo, el artículo 40 ibídem establece una excepción al régimen de libre entrada y libre competencia en el mercado. Se hace referencia a las áreas de servicio exclusivo. Las comisiones de regulación tienen la potestad de reglamentar las condiciones generales en relación con la verificación de los motivos que permiten la inclusión de estas áreas en los contratos. Por su parte, estas áreas serán constituidas por la entidad o entidades territoriales, quienes someterán sus conclusiones a la comisión de regulación correspondiente, y estas a su vez verificarán el cumplimiento de las regulaciones de carácter general.

En términos más sencillos, las comisiones de regulación expiden una regulación general, las entidades territoriales estudian y deciden sobre su inclusión, y la comisión de regulación verifica en el caso concreto el cumplimiento de la regulación general y expide un acto administrativo autorizando este modelo alternativo de prestación de los servicios.

Estos dos son los dos modelos de la Ley 142 de 1994 en los cuales existe competencia ${ }^{49}$. En el primer caso existe libre entrada y competencia en el mercado, en el segundo también existe competencia, sin embargo, se trata de competencia por el mercado. La competencia por el mercado, a diferencia de la tradicional competencia en el mercado, se refiere a escenarios especiales en los cuales la particularidad del sector o determinadas situaciones recomiendan introducir un proceso de selección o subasta para que los participantes compitan entre sí para obtener la posición de operador monopolístico ${ }^{50}$. En este caso los potenciales prestadores compiten entre sí por el derecho a ser monopolista en una de las áreas determinadas por la entidad territorial, de allí proviene el apelativo área de servicio exclusivo.

Para que el modelo de competencia por el mercado exista legalmente se deben haber satisfecho todos los requisitos, sustantivos y procedimentales, puesto que se trata de un modelo de excepción. El hecho de que la competencia

48 Richard Whish y David Bailey, Competition Law, Oxford: Oxford University Press, 8. a ed., 2015. Mauricio Velandia, Derecho de la competencia y del consumo, Bogotá: Universidad Externado de Colombia, 2. ${ }^{a}$ ed., 2011.

49 La prestación excepcional por parte del municipio constituye un tercer tipo de modelo de prestación, pero es un caso sin competencia, por lo cual resulta irrelevante dado el objeto de este artículo.

50 Michael Klein y Philip Gray, "Competition in network industries - Where and how to introduce it", en Public Policy for the Private Sector, 1997, disponible en: http://www-wds. worldbank.org/external/default/WDSContentServer/WDSP/iB/1997/01/01/000009265_398 0420172725/Rendered/PDF/multi0page.pdf [consultado el 5 de mayo de 2017]. 
por el mercado sea la excepción confirma que la competencia en el mercado debe ser la regla general.

Adicionalmente, vale la pena mencionar que el régimen legal considera la competencia tan importante que incluso en el caso en que otros objetivos recomienden un modelo alternativo a la libre competencia se opta por la competencia bajo determinadas reglas especiales, la competencia por el mercado.

El único caso en el que se autoriza la prestación directa por parte del municipio está establecido en el artículo 6 de la Ley 142 de 1994, caso para el cual se establecen requisitos aún más exigentes que para la creación de áreas de servicio exclusivo, y además se aclara que esta autorización no puede entenderse como la creación de un monopolio de derecho. Es decir que el artículo 6 no puede utilizarse como una excusa legal para excluir la competencia de los demás operadores, sino que debe usarse con los claros objetivos allí señalados.

A la luz de lo anterior, y de lo señalado por el artículo 34 de la Ley 142 de 1994, resulta clara la importancia que tiene el derecho de la competencia en el régimen de este tipo de servicios. A pesar de esta claridad, se había prestado poca atención a los servicios públicos domiciliarios desde el derecho de la competencia, hasta la expedición de la Resolución 25036 de 2014 expedida de la SIC. Ese acto administrativo constituye un punto fundamental en relación con la manera como el régimen del derecho de la competencia impacta el régimen de los servicios públicos domiciliarios.

El Distrito Capital, entre otros, a través del Decreto 564 de 2012, estableció un modelo para la prestación del servicio público de aseo que presentaba las siguientes características.

Según las consideraciones del decreto, con ese modelo de prestación del servicio se pretendía dar cumplimiento a las órdenes de la Corte Constitucional en el sentido de incluir acciones afirmativas a favor de los recicladores ${ }^{51}$. La Corte había dejado sin efecto una licitación pública por no haberse tenido en consideración la inclusión de los recicladores.

El artículo 2 del decreto establecía que se trataba de un modelo de carácter transitorio, y se ordenaba a la entidad responsable continuar con los trámites de contratación de las áreas de servicios exclusivo en el artículo 4 .

El elemento crítico del decreto estaba en el artículo 8, en el cual se estableció que la prestación se podría hacer a través de ESP pertenecientes al Distrito a través de convenios o contratos celebrados por la Unidad Administrativa Especial de Servicios Públicos (UAESP), una entidad descentralizada del orden distrital. Además se mencionó en dicho artículo que la Empresa de Acueducto del Distrito expediría los actos y celebraría los contratos para cumplir con este régimen. 
En otras palabras, a través del decreto se dejó claro que la prestación se podría hacer por empresas perteneciente al Distrito, mediante convenios o contratos celebrados por la UAESP. Se convirtió con ello a la UAESP en el titular del servicio, y quienes quisieran prestarlo deberían contar con un título habilitante.

Adicionalmente, en el artículo 9 del mismo decreto se restringió el acceso al botadero Doña Juana a aquellos que tuviesen un contrato con el operador, previa autorización de la UAESP. Nuevamente, al limitarse el acceso a esa facilidad esencial, pues el servicio no puede prestarse sin acceso a ella, lo que se hizo fue excluir a todos los operadores que la entidad, de hecho titular del servicio y titular jurídica del bien público, no deseaba en el mercado. Es decir, se estableció un típico monopolio de derecho a través de las diversas medidas contenidas en el decreto.

El esquema de prestación de servicios es más complejo, por ello no se explicará en su totalidad, y además resulta innecesario para los propósitos de este artículo.

Entre las múltiples conductas del Distrito que la SIC estudió se encontró: 1. que únicamente las empresas autorizadas por el Distrito podían prestar el servicio público de aseo en la ciudad de Bogotá; 2. que se habían tomado acciones para bloquear el acceso al relleno sanitario a aquellos operadores que no tuvieran autorización del Distrito; 3 . que la Empresa de Acueducto se había negado a hacer facturación conjunta con aquellos operadores que no contaran con autorización del Distrito, lo que creaba una desigualdad de condiciones y dificultaba la competencia de esos operadores; $y_{1}$ 4. que se había introducido la prohibición expresa para que empresas privadas prestaran el servicio so pena de que el Distrito inmovilizara sus vehículos ${ }^{52}$.

El Distrito y las demás entidades descentralizadas involucradas en el nuevo esquema de prestación intentaron varias defensas, entre las cuales llama la atención que el Distrito tratara de justificar que era él, en cuanto garante de los servicios públicos, la autoridad competente para determinar el modelo de prestación de servicios públicos domiciliarios en la capital.

Por su parte la SIC, en una verdadera interpretación pro competencia del régimen de los servicios públicos, explicó la filosofía liberalizadora de la Constitución de 1991 y de la Ley 142 de 1994. Explicó los tres modelos de prestación de servicios, y fue clara al dictaminar que la prestación directa por parte del municipio no puede usarse para constituir un monopolio de derecho.

Entendió también que la competencia en el mercado es la regla general y que las dos excepciones legales requieren de la satisfacción de los requisitos sustantivos y procedimentales que el propio régimen legal establece. De lo contrario, quien trate de sustraer el sector de los servicios públicos o alguno de 
sus subsectores estaría en contradicción de las normas del derecho de la competencia y tendría que atenerse a ser objeto de las correspondientes sanciones.

En ese sentido fue tajante al señalar que tanto los particulares como el Estado pueden prestar los servicios públicos en condiciones de libre competencia e igualdad en el mercado, sin que el Estado pueda arrogarse ventajas competitivas o privilegios en su favor o en favor de sus empresas y en perjuicio de los demás competidores del sector. Lo anterior, pues ello conllevaría una violación de la Constitución y de la Ley 142 de $1994^{[53]}$.

De tal manera, la SIC no solo favoreció la interpretación pro competencia de la ley, sino que la dotó de herramientas para hacerla realidad. Las empresas y las entidades públicas, incluyendo las entidades territoriales, deben, a partir de esta decisión, tener presente que sus acciones en relación con los servicios públicos domiciliarios pueden acarrear graves sanciones impuestas por la autoridad de competencia.

Es importante resaltar que la decisión de la autoridad distrital no había sido declarada ilegal por la jurisdicción de lo contencioso administrativo. Sin embargo, la autoridad administrativa encargada de proteger la competencia en los mercados tiene la potestad de sancionar a las autoridades que violenten la libre competencia en los servicios públicos. Ello permite concluir que los operadores que vean violentada la libre competencia en el sector de los servicios públicos domiciliarios, y posiblemente también en todos los servicios públicos liberalizados, tienen un mecanismo de protección más efectivo, más expedito, y en alguna medida más técnico que una demanda ante el contencioso administrativo, en caso de que las violaciones provengan de una autoridad administrativa.

De manera anecdótica resulta relevante señalar que las multas a las entidades involucradas alcanzaron, de manera conjunta, en esa decisión los 132.600 salarios mínimos mensuales legales vigentes, y la multa a una persona natural, de manera individual, alcanzó los 666 salarios mínimos.

Es imposible saber la suerte que estas decisiones administrativas, que han sido demandadas, van a tener en los estrados judiciales. Sin embargo, salvo que la jurisdicción de lo contencioso determine que la SIC no tiene competencia sobre los servicios públicos domiciliarios, un escenario que se considera poco probable, lo que existe es un mensaje claro por parte de la autoridad de competencia en el sentido de que la competencia importa en los servicios públicos domiciliarios. Los operadores tienen una garantía de que la libre competencia y la igualdad de condiciones van a ser respetadas, y en caso de que se sientan violentados en sus derechos pueden hacerlos exigibles con un régimen que otorga herramientas para ello. 


\subsection{Manifestaciones PARTICULARES DE LA LibRE COMPETENCIA}

EN EL RÉGIMEN DE LOS SERVICIOS PÚBLICOS DE TELECOMUNICACIONES

El último caso que será objeto de análisis en este escrito hace parte del subsector de los servicios públicos de telecomunicaciones. El contexto general de la competencia en el régimen de estos servicios se presentó en la primera parte de este escrito.

La decisión del Consejo de Estado ${ }^{54}$ que se pasa a analizar había sido sugerida en otro lugar como una decisión en la cual se había adoptado el criterio interpretativo in dubio pro concurrentia ${ }^{55}$; las razones por las cuales se considera que existe este criterio interpretativo se pasan a explicar a continuación.

La decisión del Consejo de Estado se dio con ocasión de una acción de nulidad interpuesta en contra del acto administrativo de la Comisión Nacional de Televisión (CNTV) que ordenó la apertura de la licitación pública para la adjudicación de un canal de televisión, el llamado "tercer canal". La demanda esencialmente atacaba la posibilidad establecida en los pliegos de condiciones de adjudicar el tercer canal aún en caso de que existiera un único proponente ${ }^{56}$.

El artículo legal que reglamentaba la adjudicación de este contrato era el artículo 72 de la Ley 1341 de 2009 que dispone unas reglas para los procesos de asignación de espectro con pluralidad de interesados. Esa norma, esencialmente, exige de las autoridades administrativas que previo al proceso de otorgamiento del permiso de uso de espectro o de concesión de servicios que incluya una banda de frecuencias se determine si existe un número plural de interesados. Posteriormente, la norma exige que en caso de que exista dicho número plural se deben aplicar los procesos de selección objetiva, incluido entre ellos la subasta inversa.

54 Consejo de Estado, Sala Plena de lo Contencioso Administrativo. Sentencia de 14 de febrero de 2012, exp. 11001-03-26-000-2010-0036-01 (IJ).

55 Sebastián Barreto Cifuentes, "Repensar el derecho de la contratación estatal desde la competencia", Revista digital de Derecho Administrativo, Universidad Externado de Colombia, vol. 15, 2016.

56 El numeral 4.11 de los pliegos demandados establecía:

"4.11. Obligatoriedad de la Oferta para el Proponente Habilitado Único.

"De conformidad con el artículo 90 del Decreto 2474 de 2008, la Comisión Nacional de Televisión podrá adjudicar el Contrato cuando sólo se haya presentado una Propuesta, y ésta cumpla con los requisitos habilitantes exigidos, y siempre que la oferta satisfaga los requerimientos contenidos en el Pliego.

"En el evento en que sólo resulte un Proponente Habilitado, y si la Comisión Nacional de Televisión decidiera adjudicar a éste la Concesión, dicho Proponente acepta por el solo hecho de la presentación de la Propuesta, que pagará por concepto de su Oferta Económica para Competir y Ser Elegido el diez por ciento (10\%) del Precio Base de la Concesión. En tal evento, el Precio de la Concesión será de \$113.749.900.000, que corresponde al Precio Base de la Concesión de $\$ 103.409 .000 .000$ más $\$ 10.340 .900 .000$, por concepto de la Oferta Económica para Competir y ser Elegido" (fols. 57 a 185 c. ppal.). 
Esta norma constituye un desarrollo de la libre competencia en los servicios públicos de telecomunicaciones, pues busca que en el caso de asignaciones de espectro se corrobore la existencia de una pluralidad de interesados, y que, en caso de que exista, se utilicen los procedimientos administrativos establecidos por la ley para que los interesados compitan entre ellos, esto es, los procedimientos de selección objetiva.

En ese artículo se les da la orden, a las entidades estatales encargadas de asignar espectro, de: 1 . antes de iniciar el proceso de adjudicación, verificar si existe una pluralidad de interesados, y 2. en caso de existir un número plural de interesados, proceder a usar los procesos de selección objetiva.

Esta norma, como lo plantean los salvamentos de voto a la decisión sobre la medida cautelar de suspensión provisional, y la defensa de la entidad demandada y sus coadyuvantes, admite dos interpretaciones. La primera es la interpretación literal, según la cual la obligación de verificar la pluralidad de oferentes inicia y se acaba antes de la apertura del proceso de selección de apertura.

La segunda interpretación es de carácter sistemático y se realiza con base en el criterio interpretativo pro competencia, o in dubio pro concurrentia, en donde el deber de verificar la pluralidad de interesados se extiende en el tiempo a lo largo del procedimiento de selección del adjudicatario y exige no solo la pluralidad de interesados antes del proceso de selección, sino también de oferentes durante dicho proceso. Esta última, según se entiende de la sentencia analizada, fue la interpretación adoptada por el Consejo de Estado.

$\mathrm{Al}$ igual que para el caso de los servicios públicos domiciliarios, existe en el régimen de los servicios públicos de telecomunicaciones una norma que ordena tener en consideración la libre competencia como criterio interpretativo. Se hace referencia al artículo 7 de la Ley 1341 de 2009 que expresamente establece: "Criterios de interpretación de la Ley. Esta Ley se interpretará en la forma que mejor garantice el desarrollo de los principios orientadores establecidos en la misma, con énfasis en la promoción y garantía de libre y leal competencia y protección de los derechos de los usuarios".

El Consejo de Estado reconoció la existencia de este mandato legal al interpretar el régimen legal, de tal manera que la interpretación adoptada favoreciera la competencia de los actores económicos por el mercado. Esa corporación señaló que había una remisión interpretativa del legislador al concepto de libre y leal competencia y que ello, en tanto parte de la Constitución económica, hace parte de los elementos propios de la vida democrática de nuestra sociedad ${ }_{i}$ lo cual se conecta con el interés general y hace que el legislador lo haya vinculado con cualquier lectura que se hiciera de la Ley 1341 de $2009^{[57]}$. 
El texto es absolutamente claro, pues se reconoce la competencia como criterio interpretativo de las normas jurídicas. En una lectura sistemática del régimen jurídico de estos servicios públicos, el legislador quiso que los operadores consultaran la competencia para decidir entre las múltiples alternativas que se presentan al interpretar una norma. Esta última fue la orden que se considera cumplió a cabalidad el Consejo de Estado. En efecto, así lo reconoció expresamente cuando señaló: "Sobre el conjunto de las anteriores consideraciones se ha construido en el ordenamiento colombiano un concepto de libre competencia que irradia las reglas establecidas en el artículo 72 de la Ley 1341 de 2009 a partir de su sometimiento a un concreto y definido marco de principios estructurantes del contenido material de esta libertad económica" ${ }^{\prime 58}$.

El máximo órgano de lo contencioso administrativo no rechaza la existencia de otras posibles interpretaciones, pero privilegia aquella, o aquellas, que consulten la libre competencia. En esa misma línea argumentativa, en una frase que por sí misma parece una crítica a las decisiones que han discriminado entre los diferentes ESP, se señaló:

El postulado en consecuencia gira en torno a la igualdad ante la ley, la igualdad de protección y la igualdad de trato por las autoridades, así como el deber del Estado de adecuar las condiciones para lograr que la igualdad sea real y efectiva, en todo momento y lugar. Implica por elemental garantía, que todo criterio diferenciador tan solo puede provenir de la voluntad general depositada bajo esquemas democráticos en el legislador ${ }^{59}$.

En efecto, una interpretación en este sentido, bajo normas muy similares a las que existen para los servicios públicos domiciliarios, parece contradictoria, pues en aquel tipo de servicios, tal como se demostró, sí que se han establecido criterios diferenciadores; la mayoría de ellos de origen jurisprudencial, lo que agrava aún más la crítica que podría hacerse al Consejo de Estado con base en su propia jurisprudencia.

Finalmente, para concluir con este acápite, se debe recordar que el Consejo de Estado decidió que la no presencia de un número plural de oferentes rompería el principio de igualdad y significaría la adopción de formas encubiertas de discriminación, lo que menoscabaría la libre competencia económica y las normas legales que ordenan que las interpretaciones del régimen jurídico respeten dicho principio. A la luz de lo anterior, el Consejo de Estado accedió a declarar la nulidad de la norma jurídica demandada.

Finalmente, vale la pena anotar que no es posible establecer a partir del contenido de la decisión analizada si el Consejo de Estado extenderá este nuevo

58 Consejo de Estado, Sala Plena de lo Contencioso Administrativo. Sentencia de 14 de febrero de 2012, exp. 11001-03-26-000-2010-0036-01 (IJ). Ibíd. 
tipo de interpretación, o al menos el criterio de interpretación pro competencia, a otros servicios públicos o a otros campos en donde haya competencia por el mercado. Lo anterior resultaría una buena idea para los servicios públicos domiciliarios dada la actual diferenciación injustificada entre operadores en donde hay capital público respecto de los demás. En similar sentido es posible argüir que en la contratación estatal hay recurrentemente una competencia por el mercado, pues los oferentes compiten por resultar adjudicatarios de un contrato, y allí también podría existir una interpretación pro competencia.

La pregunta permanece abierta en relación con el verdadero alcance que tendrá este criterio en el futuro. Sin embargo, no parece descabellado pensar que se puede extender a otras áreas de decisión del Consejo de Estado, especialmente si se tiene en consideración que la sentencia analizada fue proferida por la sala plena de lo contencioso administrativo.

\section{CONSIDERACIONES FINALES}

La liberalización de los servicios públicos, o al menos la posibilidad de liberalizarlos por medio de la ley, que estableció la Constitución de 1991 exige que las garantías constitucionales para las actividades económicas también estén presentes en estos servicios. Entre estas garantías constitucionales, desarrolladas por la ley, está la libre competencia económica, según la cual los actores deben competir en igualdad de condiciones de manera que puedan lograrse los beneficios económicos que normalmente se obtienen de la competencia entre actores en el mercado.

El legislador, consecuente con ello en los servicios públicos analizados, los dos liberalizados, estableció regímenes legales en los cuales se respeta la libre competencia.

En el caso de los servicios públicos domiciliarios dispuso un régimen jurídico único, a pesar de algunas pequeñas diferencias en razón de la naturaleza pública de algunos sujetos. A pesar de ello, varias decisiones judiciales han menoscabado esa igualdad de regímenes jurídicos, creando cada vez mayores diferencias. Con ello se ha desconocido que la Ley 142 de 1994 establece que sus normas deben ser interpretadas teniendo en cuenta la libre competencia, y allí la igualdad de condiciones, incluida la igualdad de regímenes jurídicos.

También para el caso de los servicios públicos domiciliarios se repasaron de manera rápida los modelos de prestación y se puso de presente una consecuencia elemental de haber introducido un régimen de libre competencia: la aplicación para el sector de las normas del derecho de la competencia.

En este sentido, se puso de presente que la autoridad de competencia puede sancionar cuando los operadores públicos, o las autoridades públicas, traten de usar sus potestades, normativas o de otro tipo (como la titularidad de una facilidad esencial), para menoscabar la competencia en el sector. 
En otras palabras, esa decisión puso de presente que la autoridad de competencia tiene las herramientas necesarias para actuar como un protector de la igualdad de condiciones y la libre competencia en general. Quizás sin la posibilidad de corregir las diferencias de régimen creadas por las autoridades judiciales en sus decisiones, pero con la potencialidad de corregir las diferencias que traten de crear artificialmente las autoridades administrativas.

Por último, en el artículo se trae a colación una decisión del Consejo de Estado sobre el servicio público de telecomunicaciones, en la cual es clara la existencia de una interpretación pro competencia o in dubio pro concurrentia. Ante dos o más interpretaciones posibles, el Consejo de Estado fue claro en que, en razón de este principio, de origen legal para el caso de estos servicios, debía privilegiarse aquella que favoreciera la libre competencia y la igualdad de competencia. En esa medida, determinó ilegal la posibilidad de asignar espectro sin la debida competencia por el mercado; es decir, declaró ilegal la posibilidad de adjudicar acceso al espectro cuando se presentaran subastas de un solo operador.

Con base en esta decisión se pudo criticar toda la línea jurisprudencial que ha venido acrecentando las diferencias de regímenes jurídicos entre los diferentes tipos de empresas de servicios públicos domiciliarios, precisamente por generar lo que la última decisión del Consejo de Estado pretendió evitar: una desigualdad de condiciones entre sujetos que compiten en el mismo mercado.

La pregunta en relación con el verdadero alcance de ese criterio interpretativo permanece. Debe ser el propio Consejo de Estado en nuevas decisiones quien decida ese alcance; alcance que de ser consecuentes debería cobijar a los servicios públicos domiciliarios para recorrer en reversa el camino lleno de atentados contra la igualdad de condiciones y la igualdad de régimen jurídico en ese sector.

Finalmente, es posible concluir que en términos generales la libre competencia está presente como garantía para la actividad económica, en mayor o menor medida, en aquellos casos en los que la Constitución, la jurisprudencia y la doctrina esperan que haya un régimen inspirado en la libre competencia. En otras palabras, con base en este corto estudio es posible concluir que la competencia es un principio, una garantía, y se manifiesta de diversas formas en los diferentes regímenes de los servicios públicos, al menos en los dos que fueron objeto de análisis en este artículo. 


\section{BIBLIOGRAFÍA}

Arneson, Richard. "Equality of opportunity", The Stanford Encyclopaedia of philosopby, Stanford: Stanford University, 2015. Disponible en: https://plato.stanford.edu/ cgi-bin/encyclopedia/archinfo.cgi?entry=equal-opportunity

Barreto Cifuentes, Sebastián. "Repensar el derecho de la contratación estatal desde la competencia", Revista digital de Derecho Administrativo, Universidad Externado de Colombia, vol. 15, 2016, pp. 297-304.

Bitrán, Gabriel y Valenzuela, Eduardo. "Water services in Chile: Comparing private and public performance", Washington, D.C.: The World Bank, 2003. Disponible en: http://documents.worldbank.org/curated/en/455861468769468006/ pdf/261260viewpoint.pdf [consultado el 5 de mayo de 2017].

Bognetti, Giuseppe y Obermann, Gabriel, "Liberalization and privatization of public utilities: Origins of the debate, current issues and challenges for the future", Annals of Public and Cooperative Economics, vol. 79, n. ${ }^{\circ}$ 3-4, 2008, pp. 461-485.

Correa Henao, Magdalena. Libertad de empresa en el Estado social de derecho, Bogotá: Universidad Externado de Colombia, 2008.

Delmon, Jefrerey. "Approaches to private participation in water services: A toolkit", Washington, D.C.: World Bank, 2006. Disponible en: http://ppp.worldbank.org/ public-private-partnership/sites/ppp.worldbank.org/files/ppp_testdumb/documents/ ApproachestoPrivateParticipationWaterServices.pdf [consultado el 5 de mayo de 2017].

García, José. "Liberalización, cambio estructural y crecimiento económico en Colombia", Cuadernos de Economía, vol. 21, n. ${ }^{\circ}$ 36, Bogotá: Universidad Nacional de Colombia, 2002, pp. 189-244.

Ariño, Gaspar. Principios de derecho público económico, Bogotá: Universidad Externado de Colombia, 2003.

Henao, Juan Carlos. "Estado social y derecho administrativo", en La constitucionalización del derecho administrativo, XV Jornadas Internacionales de Derecho Administrativo, en AlBERTO Montaña Plata y Andrés Fernando Ospina Garzón (eds.), Bogotá: Universidad Externado de Colombia, 2014, pp. 147-201.

Jones, Alison y Sufrin, Brenda, EU Competition Law: Text, Cases and Materials, Oxford: Oxford University Press, 5. ${ }^{\mathrm{a}}$ ed., 2016.

Klein, Michael y Gray, Philip, "Competition in network industries - Where and how to introduce it", en Public Policy for the Private Sector, 1997. Disponible en: http:// www-wds.worldbank.org/external/default/WDSContentServer/WDSP/IB/1997/01/ 01/000009265_3980420172725/Rendered/PDF/multi0page.pdf [consultado el 5 de mayo de 2017]. 
Montaña Plata, Alberto. "Alcances de la libertad económica privada en el régimen de servicios públicos introducido por la Constitución de 1991", Revista Derecho del Estado, Universidad Externado de Colombia, vol. 14, 2003, pp. 197-210.

Montaña Plata, Alberto. El concepto de servicio público en el derecho administrativo, Bogotá: Universidad Externado de Colombia, 2005.

Montaña Plata, Alberto. "La desconfiguración del régimen jurídico de los servicios públicos domiciliarios a partir de la calificación de entidades públicas a las empresas de servicios públicos mixtas", Revista digital de Derecho Administrativo, Universidad Externado de Colombia, vol. 3, 2010, pp. 163-190.

Quijano, Henry. "Propuesta de Reformas institucionales, legislativas y regulatorias a la política pública de servicios públicos domiciliarios de agua potable y saneamiento", Revista Ópera, n. ${ }^{\circ}$ 4, Universidad Externado de Colombia, 2004, pp. 115-146.

Rincón CóRdoba, JoRge IvÁN. "La igualdad material como responsabilidad de la administración pública", en Alberto Montaña Plata y Andrés Fernando Ospina GARZÓN (eds.), La constitucionalización del derecho administrativo, XV Jornadas Internacionales de Derecho Administrativo, Bogotá: Universidad Externado de Colombia, 2014, pp. 419-449.

Sánchez Graells, Albert. Public Procurement and the EU Competition Rules, Oxford: Hart Publishing, 2015.

Santofimio Gamboa, Jaime Orlando. Tratado de derecho administrativo, Bogotá: Universidad Externado de Colombia, 2004

Shirley, Mary Y Walsh, Patrick. "Public versus private ownership: The current state of the debate", Working paper, World Bank, 2001.

Uprimny, Rodrigo y Rodríguez, César. "Constitución y modelo económico en Colombia: hacia una discusión productiva entre economía y derecho". Disponible en: http://www.dejusticia.org/files/r2_actividades_recursos/fi_name_recurso.775.pdf [consultado el 8 de mayo de 2017].

Vargas Ayala, Guillermo. "El control judicial del contencioso administrativo en servicios públicos", Con-texto, Universidad Externado de Colombia, n. ${ }^{\circ} 42,2014$, pp. 11-35.

Velandia, Mauricio. Derecho de la competencia y del consumo, Bogotá: Universidad Externado de Colombia, 2. ${ }^{\text {e }}$ d., 2011.

Whish, Richard y Bailey, David. Competition Law, Oxford: Oxford University Press, 8. ${ }^{\mathrm{a}}$ ed., 2015. 